\title{
The effects of precipitation variability on the canopy cover of forage species in arid rangelands, Iran
}

\author{
Hamed Joneidi ${ }^{1,2} \cdot$ Nahid Azizi ${ }^{1} \cdot$ Khaled Osati $^{1,2} \cdot$ Isa Bandak ${ }^{3}$ \\ Received: 3 September 2019 / Accepted: 20 August 2020 / Published online: 10 September 2020 \\ (C) The Author(s) 2020
}

\begin{abstract}
This research was conducted to monitor changes in canopy cover of typical species during a 10-year period in the part of arid rangelands, to find out the relationship between two important climate variables (precipitation and temperature) and canopy cover changes. For that reason, canopy cover percentages of six dominant perennials and all annual plant species combined were measured during a 10-year period at phenological maturity of plant in thirty $2 \mathrm{~m} \times 2 \mathrm{~m}$ plots which were placed along two 250 - $\mathrm{m}$ transect lines. The results demonstrated that the maximum canopy cover for water year 2006-2007 (wet year) and the minimum value for water year 2012-2013 (drought) were 15 and 5.5\%, respectively. The canopy cover was modeled by linear regression in which precipitation and temperature variables were considered independent variables. April precipitation explained $65 \%$ of changes in the canopy cover percentage of Artemisia sieberi at 95\% confidence level (RRMSE $=0.26$ and MAE $=0.49$ ). The best simple linear regression models for estimating canopy cover percentages of Stipa barbata and Zygophyllum eurypterum corresponded to cumulative 4-month precipitation from March to June and March precipitation respectively, representing 77\% (at 99\% confidence level) and 67\% (at 95\% confidence level) of changes correspondingly. Considering the dominance of A. sieberi, S. barbata, and Z. eurypterum in floristic composition of the study area, it can be concluded that most changes in canopy cover of the studied rangeland are predicted by variability of precipitation during growing seasons.
\end{abstract}

Keywords Canopy cover $\cdot$ Climate variability $\cdot$ Precipitation $\cdot$ Linear regression

\section{Introduction}

Sustainable exploitation of rangelands in arid regions needs the knowledge of variation in vegetation cover and the effective

Responsible Editor: Amjad Kallel

Hamed Joneidi

h.joneidi@uok.ac.ir

Nahid Azizi

nahid.azizi9@gmail.com; h.joneidi@uok.ac.ir

Khaled Osati

K.Osati@uok.ac.ir

Isa Bandak

isabandak@gmail.com

1 Faculty of Natural Resources, University of Kurdistan, Sanandaj, Iran

2 Kurdistan Studies Institute, University of Kurdistan, Sanandaj, Iran

3 University of Tehran, Tehran, Iran factors influencing it (Walter 1979; Abdolahi et. al. 2012; Abdolahi et al. 2011a, b). Successive measurements over several years are necessary to achieve such data which is valuable for rational exploitation planning of rangelands at national level (Arzani 1997). Contrary to the temperature regime and soil properties, which undergo little fluctuations, the productivity of the rangelands is much more affected by the characteristics of the rains, in particular their quantities (Akbarzadeh and Mirhaji 2007). Not just the amount of rain but the changes in the frequency of it is critical (Damizadeh et al. 2001). This is why seasonal variations are more indicative than annual cumulations (Akbarzadeh and Mirhaji 2007). The water scarcity following the weak precipitation and the strong evapotranspiration which characterize the arid and semi-arid ecosystems constitutes a major limiting factor for the growth and the production of plant (Hennessy et al. 1998; Munkhtsetseg et al. 2007).

Arid and semi-arid areas are characterized by low precipitation and intensive fluctuations in precipitation at daily, seasonal, and annual scales (Noy-Meir 1973). Frequency and temporal distribution of precipitation play an important role in soil water availability and affect the vegetation cover of arid regions 
extremely (Ehleringer et al. 1999). As the potential evapotranspiration is several times greater than precipitation in arid and semi-arid areas, the growing season precipitation cannot meet the plant water demand alone. Therefore, plant species have to adapt to use the stored soil water from previous precipitation events. This implies the important role of autumn and winter precipitation (Hein 2006) for plant species in arid and semi-arid regions. Precipitation occurring during winter is more likely to percolate through the soil, while that occurring during spring and summer may evaporate before infiltrating the soil (Schwinning et al. 2003). However, there is a unique precipitation regime within every climatic region and the local assessment of precipitation variation is then necessary.

Rangelands consist of different plant types each having its own diverse species which are characterized by different qualitative and quantitative vegetative attributes, diverse phenological stages, and various vegetative forms (Zare Kia 2015). Therefore, the plant responses to and dependences on precipitation are different depending on vegetative form and root system in combination with the spatial and temporal distribution of precipitation. The floristic composition and plant production are not therefore constant. The estimation of constant carrying capacity is then complicated due to the inter-annual variation in plant productivities where the annual species are more affected than perennial ones (Moghaddam 1998).

Many studies have been conducted on the effect of climatic variability on canopy cover and the productivity of rangeland species (Jabbogy and Sala 2000; Paruelo and Lauenroth 1996; Raynaud and Leadley 2004). Having investigated 9-year data of canopy cover of different species within steppe areas of Shoor River, Akbarzadeh and Mirhaji (2007) stated that the canopy cover of perennial species had decreased up to $40 \%$ over that period. This decrease was lower in Gramineae and more in broad-leaved plant. Hennessy et al. (1998) also had reported the same results for the period 1990- 94 suggesting a onethird decrease in canopy cover of Axonopus affinis as dominant species. Studies of Abdollahi et al. (2011a, b) on rangelands of Yazd province (Iran) demonstrated that most plant species responded to the precipitation variation with the responses of vegetation cover and productivity to the precipitation variation being different among diverse species. The correlation of the canopy cover of total species as well as the canopy cover of Artemisia aucheri with the winter precipitation was significantly negative while the precipitation from January to April and the precipitation of the previous year showed the highest correlation with the canopy cover of Iris songarica and Stipa barbata. Ghelichnia et al. (2012) concluded that the vegetation cover of rangelands of Mazandaran province (Iran) was dominantly affected by variation in precipitation. They reported significant positive relationships between annual precipitation and both production and canopy cover at most study sites. Hosseini et al. (2014) investigated the variation in vegetation cover of semi-steppe rangelands of Golestan province (Iran) and stated that those variations in vegetation cover of perennial Gramineae and broad-leaved forbs were affected by the precipitation while the variation in canopy cover of Cynodon dactylon did not show a positive correlation with precipitation and the variation in vegetation cover of Poa bulbosa was affected by spring precipitation, particularly by May precipitation (Karimi et al. 2015). During 1998-2007, Bayat et al. (2016) obtained the best relationship for estimating the annual cover of steppe rangelands of Alavije and Khondab in Isfahan province (Iran) on the basis of relative humidity, December temperature, and annual precipitation. They also stated that the effect of climatic condition on canopy cover and annual production of different vegetative forms were not similar. Sharifi et al. (2017) monitored the canopy cover of summer rangelands of Agh-Dagh in Khalkhal (Iran) during 2008-2012. The results showed that during the 4-year studied period, the perennial Gramineae played the main role in plant canopy cover variation that were associated with variation in precipitation and the temperature. The annual variation in canopy cover of perennial Gramineae including Bromus tomentellus and Agropyron cristatum was significant while in the case of shrubs, the variation was minor and statistically insignificant. Having conducted a study at Great Basin region in America, Bradley and Mustard (2005) stated that the vegetative forms and canopy cover of plant are important factors in their responses to precipitation. In the studied region, rangelands with vegetative forms of grass were reported as the most sensitive form to the variation in precipitation. The decrease in canopy cover in response to decrease in precipitation has been reported by various authors including AnLin et al. (1994), Moyo et al. (1995), Ligan et al. (1998), and Drawe (1999).

Previous studies revealed specific responses of plant species toward the variability of precipitation and temperature. Responses of plant species are mainly dependent on vegetative form of a plant and the temperature and precipitation regimes which is not studied well yet. Therefore, this study was conducted with the aim of monitoring the effect of climatic variability on the canopy cover of dominant plant species having different vegetative forms including Artemisia sieberi (bush), Ephedra intermedia (shrub), Zygophyllum eurypterum (shrub), Stipa barbata (perennial grass), Scariola orientalis (perennial forb), Anabasis setifera, and annual species (mainly Salsola crassa) of Ghosheh rangelands in Semnan (Iran).

\section{Materials and methods}

\section{Study area}

The study site with the area of 1140 ha and an average elevation of $1330 \mathrm{~m}$ above sea level was located at Panj-Koh, about $6 \mathrm{~km}$ far from Ghosheh village at $35^{\circ} 54^{\prime} 17^{\prime \prime}$ to $35^{\circ} 56^{\prime} 04^{\prime \prime} \mathrm{N}$ and $54^{\circ}$ $00^{\prime} 03^{\prime \prime}$ to $54^{\circ} 03^{\prime} 56^{\prime \prime} \mathrm{E}$ (Fig. 1). The study area is located on a $70-\mathrm{cm}$ soil depth in sandy loam soil (68.8\% sand, $16.4 \%$ silt, and 

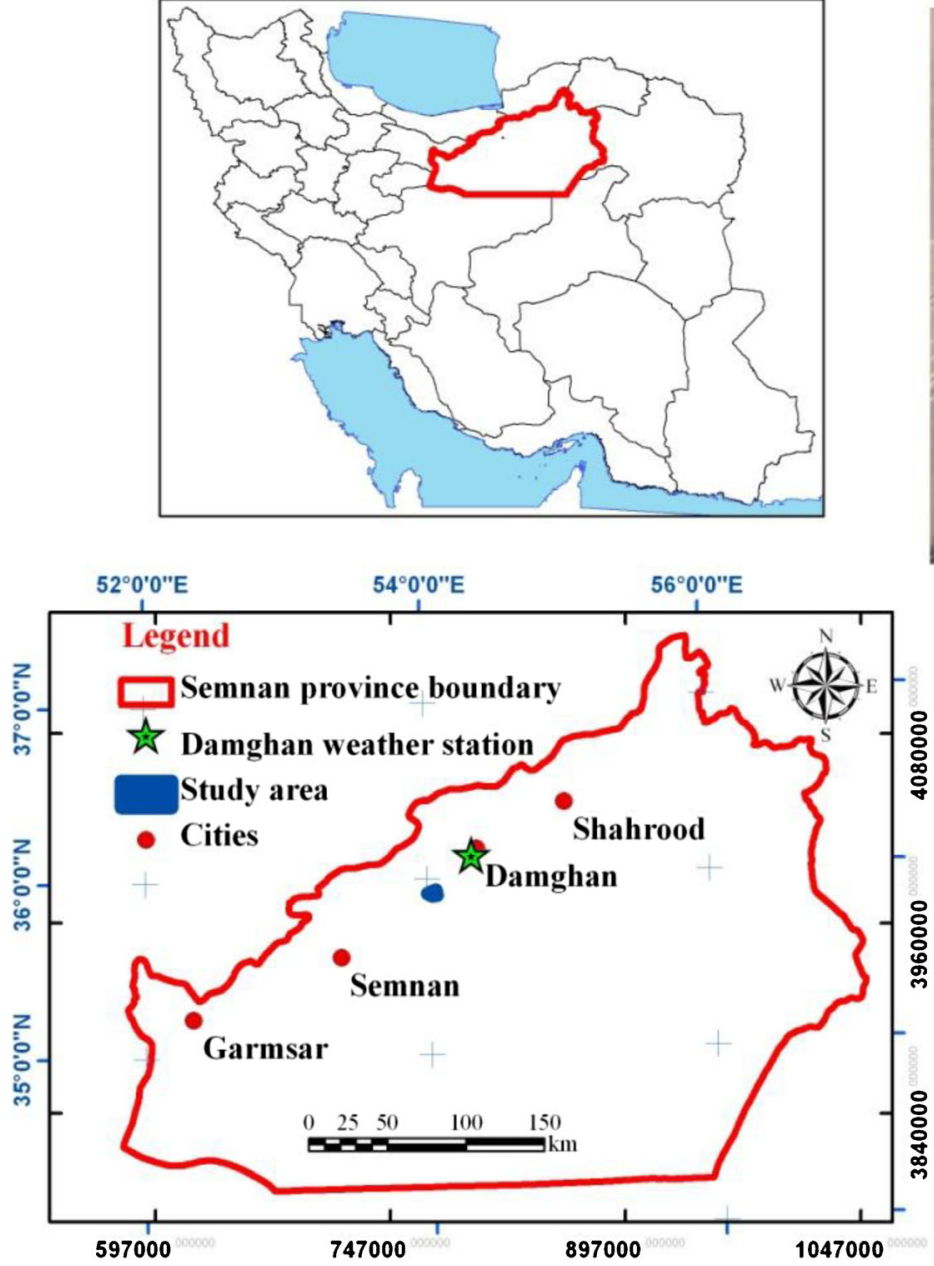

Fig. 1 Location of the study area in Semnan province, Iran

$14.8 \%$ clay) which is classified as Aridisol. The topography of the study area was piedmont plain with the general slope of $4 \%$ at northern direction having a good drainage density (Joneidi Jafari 2009). Dominant plant species of the study area were Artemisia sieberi, Ephedra intermedia, Zygophyllum eurypterum, Stipa barbata, Scariola orientalis, Anabasis setifera, and annual species (mainly Salsola crassa) (Azarnivand et al. 2007).

According to De Martonne aridity index $(I=3.94)$, calculated on the basis of recorded data at Damghan station (water years 2005-2006 to 2014-2015), the climate of the study area is arid receiving long-term mean annual precipitation of $109.21 \mathrm{~mm}$. Ombrothermic curve of Damghan station showed that the dry season is dominant throughout the year, extending from March to January with February considered the only humid month.

\section{Methodology}

According to the aims of the study, canopy cover of six typical plant species including $A$. sieberi, E. intermedia,
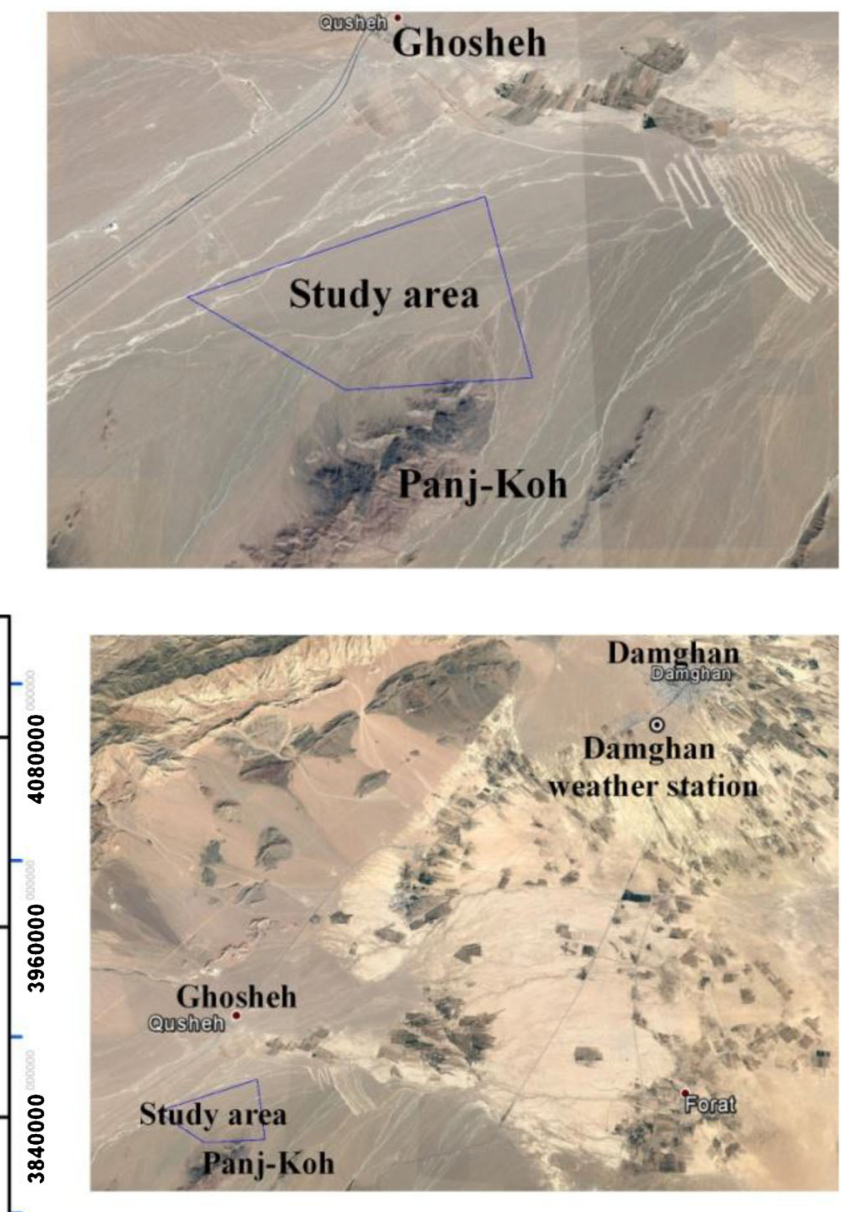

Z. eurypterum, S. barbata, S. orientalis, A. setifera, and all annual plant species combined were measured at phenological maturity of plant species (peak biomass in early May (Karami et al. 2019) during a 10-year monitoring period (between water years of 2005-2006 and 2014-2015). Transect and plot were used to monitor the canopy cover. According to the topography and vegetation cover characteristics of the study area, 2 transect lines were perpendicular to each other, in a north-south and west-east direction having the lengths of 250 and $250 \mathrm{~m}$, respectively. The percentage of canopy cover for each species was measured annually on 15 plots with the area of $4 \mathrm{~m}^{2}$ across each transect altogether 30 plots throughout the study area for each year. The least area method was used to achieve the optimal sizes and numbers of plots for sampling. Point-quadrate was used in estimation method. The transect locations were marked every year which were relocated longitudinally at the next year. Plots were arranged in a systematic random method.

The correlations among the canopy cover of species and temperature and precipitation of different months/different vegetative periods were investigated in order to evaluate the 
effect of climatic conditions on variation in plant canopy cover. According to the closeness of the study area to Damghan station (with a distance of $32 \mathrm{~km}$ ) and their climatic and topographical similarities, daily precipitation and temperature data of Damghan station were used for monitoring the climatic condition of the study area. After quality control of data and confirming their validity, monthly, multi-monthly, and annual time series were calculated for the same period as vegetation cover monitoring (between the water years of 2005-2006 and 2014-2015). The sparse distribution of precipitation throughout the year led us to investigate short periods too. In order to represent a suitable model, 34 independent variables within different time scales (including 9 monthly values, 82 -month values, 73 -month values, 64 -month values, 2 6-month values, 19 -month value, and 1 yearly value for any year) were extracted from precipitation as well as temperature time series. However, the summer precipitation was considered only in the annual time scale (precipitation of the water year) due to the time of production measurements and the low values of summer precipitation.

After the independent variables were prepared, the existing data set (including 10 years canopy cover data, 10 years climate data for 34 precipitation and 34 temperature variables) was divided into two subsets of modeling (first 8 years) and validation data (the last 2 years data, i.e., canopy cover of 2014 and 2015 was considered validation data in assessing the accuracy of modeling results). Next, the Pearson correlation coefficient was calculated on the basis of modeling subset (data of first 8 years) so that if there was a significant correlation between each independent variable and canopy cover data, then fitting the simple linear regression curve was examined. Values of precipitation and temperature at different time scales were included in model as independent variables and percent of canopy cover for annual species (overall) or the cover percentage of each six dominant perennial species were considered dependent variables. Suitable relationships at modeling stage were approved when $R^{2}$ values were significant at $95 \%$ confidence level and statistical assumptions were met (i.e., normality of residuals, considering homogeneity/ heterogeneity of variances, and proving significance of regression coefficients in regression model). Finally, the suitable model for predicting the canopy cover of species was selected according to the accuracy of proved models at validation stage on the basis of which the effects of variation in precipitation and temperature were interpreted. In order to evaluate the accuracy of prediction models at validation stage, relative root mean square error (RRMSE), mean bias error (MBE), and mean absolute error (MAE) were used. The value of RRMSE was calculated by dividing the root mean square error (RMSE) by the mean observed data. If RRMSE was less than 10 , then the simulation model was considered excellent; if RRMSE was between 10 and 20, the simulation was considered good; for RRMSE between 20 and 30, the simulation results were considered fair; and if RRMSE was more than 30, then the modeling results were considered poor (Jamieson et al. 1991). The regression relationships were analyzed using SPSS software.

\section{Results}

\section{Temporal variation in precipitation at monthly, seasonal, and annual scales}

The temporal pattern of precipitation at Damghan station over a 10-year period (water years of 2005-2006 to 2014-2015) indicated that the most precipitation occurred from February to April and there was less precipitation in summer. Temporal distribution of precipitation over the 10-year period (water years of 2005-2006 to 2014-2015) at Damghan station showed that $29.8 \%$ of precipitation occurred at spring, $15.7 \%$ at summer, $22.7 \%$ at autumn, and $31.8 \%$ at winter. The maximum annual precipitation within the 10 -year period of monitoring $(150.88 \mathrm{~mm})$ occurred at the water year 2006 2007 and mostly during the spring. The minimum $(68.78 \mathrm{~mm})$ occurred at the water year 2007-2008. The maximum values of winter precipitation were observed at the water years of 2007-2008 and 2013-2014 while the minimum values occurred during water year 2011-2012. The minimum spring precipitation occurred at the water years 2007-2008 and 2010-2011 and the maximum observed in water year 20062007. The maximum monthly precipitation of $49.6 \mathrm{~mm}$ was observed in April 2007. Although the responses of vegetative forms are different depending on climate variability, phonology, root structure, physiology, etc. are important factors which can affect the possible responses of vegetative forms (Fig. 2).

\section{Evaluation of variation in plant canopy cover and its relationship with variability of precipitation and temperature}

Changes in canopy cover of typical species during a 10-year period are represented in Fig. 3. As shown in this figure, diverse species responded differently to variation in precipitation over the studied 10-year period. The minimum canopy cover was observed for water years 2007-2008 and 20122013 due to severe decrease in precipitation. Canopy cover of $A$. sieberi and annual species represented the maximum variation over dry and wet years during which significant variation occurred in precipitation. Statistical characteristics of collected canopy cover data are summarized in Table 1.

Correlations among the canopy cover of species and the precipitation and temperature at calibration stage of different time durations (34 examined variables) were calculated using data related to the first 8 years of the study (water years 2005- 
Fig. 2 Ombrothermic diagram of the study site showing rainfall (cm) and mean temperature $\left({ }^{\circ} \mathrm{C}\right)$

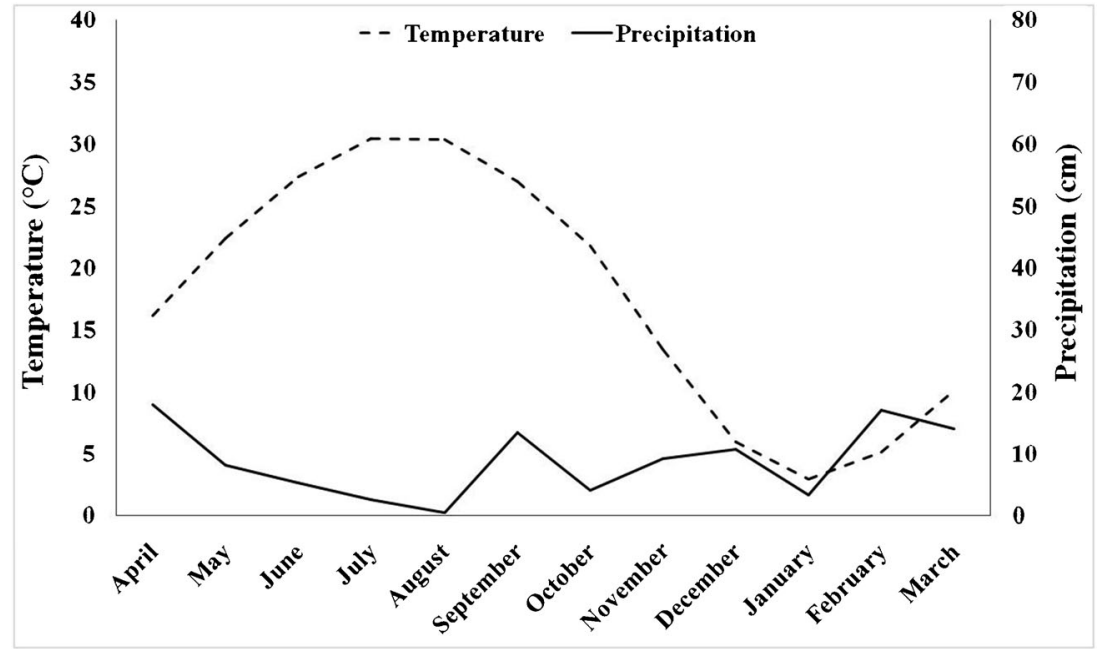

2006 to 2012-2013). There was a good correlation between variation in precipitation at different years and the canopy cover of most species, which showed a strong correlation with winter and spring precipitation. The correlation of the canopy cover of A. sieberi, S. barbata, and annual species with precipitation values was significant at $99 \%$ confidence level. A. sieberi represented the highest significant positive correlation with the 4-month precipitation from February to May at of $99 \%$ confidence level $(R=0.93)$. Annual species as well as $S$. barbata also represented the highest significant positive correlation with the 3-month spring precipitation and the 4month precipitation respectively from March to June. In the case of A. setifera, a significant correlation was only observed at $10 \%$ and there was no significant correlation in the case of E. intermedia. Simply in the case of A. sieberi, a significant reverse correlation was detected between the canopy cover and temperature. The highest correlation coefficient of $77 \%$ between the canopy cover of $A$. sieberi and the temperature belonged to April was significant at $95 \%$ confidence level. At this stage, suitable models were selected on the basis of $R^{2}$ significant values at $95 \%$ confidence level and according to achievements in statistical assumptions for the obtained regression equation (i.e., normality of residuals, considering homogeneity/heterogeneity of variances, and proving significance of regression coefficients in regression model). As statistical assumptions were not met for several regression equations (i.e., normality of residuals and proving significance of regression coefficients in regression model), it was impossible to select a suitable regression model for several variables having high correlation coefficients at modeling stage (for example, regression model for estimating canopy cover of A. sieberi by $\mathrm{P}_{28}$ was not verified in validation stage) (Table 2).

To select the final suitable model, the canopy cover at validation stage (the last 2 years of the studied period) was estimated on the basis of selected models at calibration stage and according to error indices (RRMSE, MBE, MAE); then, the results of estimating the canopy cover were compared with the observed canopy cover of species for 2014 and 2015 (Table 3). According to the obtained results, the best represented simple regression model for estimating the canopy cover of A. sieberi was on the basis of precipitation occurring in April $($ RRMSE $=0.26$, MAE $=0.49)$ which accounted for $65 \%$ of variation in the canopy cover at $95 \%$ confidence level. In the case of $S$. barbata, the simple linear model on the basis of the 4-month precipitation from March to June represented the best results accounting for $77 \%$ of variation in canopy cover of the species at 99\% confidence level (RRMSE = 0.16 , MAE $=0.10$ ). The simple linear regression model on the basis of precipitation occurring in March with

Table 1 Statistical characteristics of monitored canopy cover data (2006-2015)

\begin{tabular}{llllllll}
\hline Statistics & \multicolumn{2}{l}{ Species } & & & \\
\cline { 2 - 7 } & A. sieberi & S. barbata & Z. eurypterum & Annual plants (overall) & A. setifera & E. intermedia & S. orientalis \\
\hline Average & 2.27 & 0.84 & 2.65 & 2.06 & 1.03 & 0.33 & 0.31 \\
Maximum & 4.11 & 1.61 & 3.50 & 3.94 & 1.54 & 0.50 & 0.44 \\
minimum & 1.27 & 0.47 & 1.78 & 1.00 & 0.49 & 0.11 & 0.17 \\
Standard deviation & 0.891 & 0.312 & 0.580 & 1.037 & 0.382 & 0.120 & 0.116 \\
Coefficient of variation (CV) & 0.392 & 0.373 & 0.219 & 0.503 & 0.370 & 0.368 & 0.373 \\
\hline
\end{tabular}


Fig. 3 Variation in canopy cover over the 10-year monitoring period in response to precipitation variability

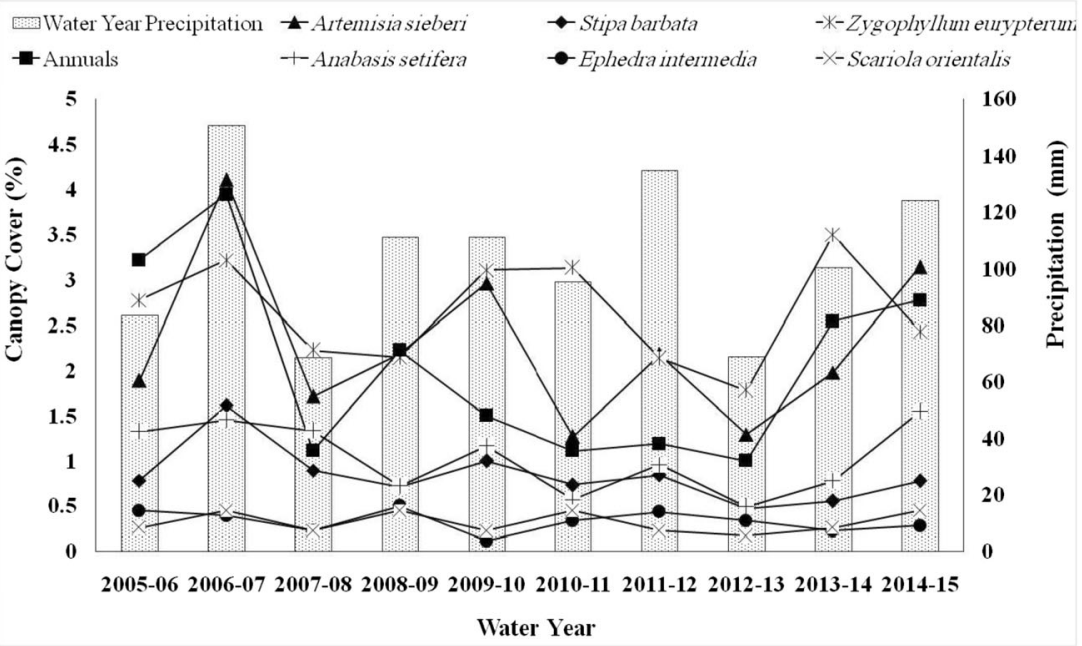

RRMSE $=0.23$ and MAE $=0.49$ accounted for $65 \%$ of variation in canopy cover of $Z$. eurypterum at $95 \%$ confidence level. In order to estimate the canopy cover of $S$. orientalis, the simple linear regression model on the basis of the 2-month precipitation occurring in March and April with RRMSE = 0.42 was used and the results of which were not citable due to high errors. The best model for estimating the canopy cover of annual species was on the basis of the 1-month precipitation occurring in April which was considered weak due to RRMSE $=0.33$ although the $R^{2}$ value is $77 \%$. There were no suitable models for estimating the canopy cover of E. intermedia and A. setifera.

\section{Discussion}

The results of a 10-year study (water years 2005-2006 to 2014-2015) at Ghosheh steppe rangelands indicated that averagely the maximum and minimum canopy cover belonged to the tree species of $Z$. eurypterum and the two $E$. intermedia and $S$. orientalis shrubs, respectively. A. sieberi with the canopy cover of $24 \%$ was the second dominant species following $Z$. eurypterum, while the maximum coefficient of variation during the wet and dry years belonged to $A$. sieberi following the annual species. Generally, precipitation was an influencing factor affecting the canopy cover of the studied rangeland species so that during the water year 2006-2007 with the mean precipitation of $150.88 \mathrm{~mm}$, the total canopy cover of the studied rangeland was $15 \%$ which decreased to $5.5 \%$ during the dry year 2012-2013 with the mean precipitation of $69 \mathrm{~mm}$. The occurrence of drought, indeed, caused the decrease in canopy cover of most studied species. Monitoring the species responses to the variation in precipitation indicated that the effect of drought on the studied species was different and the variation in canopy cover of annual species was more than those of perennial and tree species. This is indicative of different tolerance of the studied species to the occurrence of water and drought. Akbarzadeh and Mirhaji (2007) following a 9-year study on steppe areas of Shoor River stated that the occurrence of 5 dry years caused the decrease in vegetation cover by $40 \%$. They concluded that drought occurring over the water year 2007-2008 affected the canopy cover of next year so the studied rangeland experienced much less vegetation cover than the same normal year (11\% decrease) and the increase in moisture during the next year could not compensate the adverse effect of the severe drought of the previous year. Navarro et al. (2002) on studying the effect of the dry and wet years over the 48-year duration on canopy cover of Hilaria mutica and Bouteloua eriopoda in rangelands of New Mexico suggested that the occurrence of drought had neutralized the positive effect of wet year. The significant effect of drought persistence on canopy cover corresponds with the results of Herbel et al. (1972). On the basis of the obtained results over a 9-year monitoring on steppe areas of Shoor River, Akbarzadeh and Mirhaji (2007) concluded that the persistence of drought for several years (from 1997 to 2001) caused such a damage to plant that the good moisture of wet years 2002-2004 could not help for the improvement of vegetation cover.

Study on the correlation between the canopy cover and different periods of precipitation represented that the highest significant correlation coefficient with the 4-month precipitation from February to May belonged to A. sieberi $(r=0.93, P$ value $<0.01)$. In other words, the addition to the precipitation of February and March, the precipitation occurring in April and May (as the main vegetative period) played the main role in variation of canopy cover. The reason is explained by the fact that the main root of $A$. sieberi made it possible to use the water supply from winter through percolating the soil. It was also the case of $S$. barbata in which the highest correlation was found between the canopy cover of species and the 4month precipitation from March to June. There was a 
significant correlation between the canopy cover of annual species and the 3-month spring precipitation which was indicative of the severe dependence of these species on precipitation occurring during vegetative season. Kashki et al. (2015) on the investigation of variation trends and dynamics of vegetation cover in desert ecosystems of Jajarm area suggested that the precipitation and available water in 2010, coincident with growth and development of annuals (from March to May), was more than 2009 and for this reason, the annual species showed a significant increase in canopy cover.

Although with the highest variation in canopy cover due to the dependence of annual species to the moisture of soil surface layer, a considerable percentage of the total vegetation cover of the studied rangeland belonged to annual species, $Z$. eurypterum showed the least coefficient of variation in canopy cover. The vegetative form and persistent establishment of the roots within the soil can be considered the most effective factors in widely distribution of this species in steppe rangelands. According to considerable canopy cover of A. sieberi shrubs and annual species, the variation in total canopy cover was partially dependent on the variation in these species and the effective periods of precipitation played an important role in total canopy cover. It can then be stated that spring (as vegetative period) and winter were the most important periods of occurring the effective precipitation for variation in steppe rangelands of Ghosheh. The results of Akbarzadeh and Mirhaji (2007) at southern hillsides of Damavand at north part of Ploor exclusive indicated that the spring precipitation played a remarkable role in the total variations in canopy cover and accounted for more variations in total canopy cover. Currie and Peterson (1996) reported the effectiveness of precipitation occurring in April and May on the production of Agropyron cristatum. Karabulu (2002) suggested the effective role of stored water from the previous precipitation as an indicative of the direct relationship between the dynamics of plant and the available water within the soil profile. Abdollahi et al. (2011a, b) through a study on Ebrahim-Abad rangelands of Yazd province (Iran) concluded that the precipitation occurring at January to April as well as in winter affected the canopy cover of $A$. sieberi the most. Although the responses of vegetative forms are different depending on climate variability, phonology, root structure, physiology, etc. are important factors which can affect the possible responses of vegetative forms (Tasiu 2020).

\section{Conclusion}

In this study, an effort was made to represent suitable models for predicting the canopy cover of typical species through monitoring the relationship between two important climate variables (precipitation and temperature) and canopy cover changes. Study on the most suitable simple linear regression 
Table 3 Error indices values at modeling and validation stages

\begin{tabular}{|c|c|c|c|c|c|c|c|}
\hline \multirow[t]{2}{*}{ Plant species } & \multirow[t]{2}{*}{ Independent variable } & \multirow[t]{2}{*}{ Regression model* } & \multicolumn{2}{|c|}{ Results of modeling stage } & \multicolumn{3}{|c|}{ Results of validation stage } \\
\hline & & & $R^{2}$ of modeling stage & Sig & RRMSE & MAE & MBE \\
\hline \multirow[t]{8}{*}{ A. sieberi } & $\mathrm{P}_{17}$ & $Y=1.326+0.049 \mathrm{X}$ & 0.65 & 0.016 & 0.26 & 0.49 & -0.45 \\
\hline & $\mathrm{P}_{26}$ & $Y=1.156+0.037 \mathrm{X}$ & 0.71 & 0.009 & 0.43 & 0.95 & -0.95 \\
\hline & $\mathrm{P}_{27}$ & $Y=0.843+0.05 \mathrm{X}$ & 0.84 & 0.001 & 0.35 & 0.74 & -0.74 \\
\hline & $\mathrm{P}_{36}$ & $Y=0.793+0.038 \mathrm{X}$ & 0.85 & 0.001 & 0.50 & 1.16 & -1.16 \\
\hline & $\mathrm{P}_{37}$ & $Y=0.945+0.039 \mathrm{X}$ & 0.78 & 0.004 & 0.35 & 0.74 & -0.74 \\
\hline & $\mathrm{P}_{46}$ & $Y=0.808+0.033 \mathrm{X}$ & 0.85 & 0.001 & 0.49 & 1.12 & -1.12 \\
\hline & $\mathrm{T}_{13}$ & $Y=4.421-0.357 \mathrm{X}$ & 0.52 & 0.044 & 0.35 & 0.84 & -0.34 \\
\hline & $\mathrm{T}_{17}$ & $Y=8.394-0.372 \mathrm{X}$ & 0.59 & 0.026 & 0.51 & 1.31 & -0.12 \\
\hline \multirow[t]{7}{*}{ S. barbata } & $\mathrm{P}_{17}$ & $Y=0.598+0.016 \mathrm{X}$ & 0.54 & 0.039 & 0.31 & 0.19 & 0.19 \\
\hline & $\mathrm{P}_{26}$ & $Y=0.534+0.012 \mathrm{X}$ & 0.62 & 0.02 & 0.16 & 0.10 & 0.02 \\
\hline & $\mathrm{P}_{27}$ & $Y=0.443+0.016 \mathrm{X}$ & 0.69 & 0.01 & 0.19 & 0.09 & 0.09 \\
\hline & $\mathrm{P}_{28}$ & $Y=0.372+0.035 \mathrm{X}$ & 0.67 & 0.013 & 0.92 & 0.61 & 0.61 \\
\hline & $\mathrm{P}_{36}$ & $Y=0.416+0.012 \mathrm{X}$ & 0.74 & 0.006 & 0.17 & 0.10 & -0.06 \\
\hline & $\mathrm{P}_{37}$ & $Y=0.463+0.013 \mathrm{X}$ & 0.69 & 0.011 & 0.19 & 0.09 & 0.09 \\
\hline & $\mathrm{P}_{46}$ & $Y=0.412+0.011 X$ & 0.77 & 0.004 & 0.16 & 0.10 & -0.04 \\
\hline Z. eurypterum & $\mathrm{P}_{16}$ & $Y=2.058+0.049 \mathrm{X}$ & 0.67 & 0.013 & 0.23 & 0.49 & -0.48 \\
\hline S. orientalis & $\mathrm{P}_{26}$ & $Y=0.186+0.004 \mathrm{X}$ & 0.55 & 0.034 & 0.42 & 0.11 & -0.11 \\
\hline Annuals & $\mathrm{P}_{17}$ & $Y=0.785+0.063 \mathrm{X}$ & 0.77 & 0.004 & 0.33 & 0.87 & -0.87 \\
\hline
\end{tabular}

Note: Each variable is named by a Latin letter and a numerical fig. P and T letters are indicatives of precipitation and temperature variables, respectively. The first numerical figure associates with the number of months used to calculate the aggregate value and the second numerical figure refers to the order of first starting month of the period in a water year; for example, $\mathrm{P}_{46}$ is indicative of a total of 4 months of precipitation including March, April, May, and June

As statistical assumptions were not met for several regression equations (i.e., normality of residuals, considering homogeneity/heterogeneity of variances, and proving significance of regression coefficients in regression model), it was impossible to select a suitable regression model for several variables having high correlation coefficients at modeling stage (for example, regression model for estimating canopy cover of $A$. sieberi by $\mathrm{P}_{28}$ was not verified in validation stage)

relationships between different periods of precipitation and canopy cover of typical species showed that the represented models on the basis of error indices for predicting the canopy cover of A. sieberi, S. barbata, and Z. eurypterum were suitable while those for predicting the canopy cover of other species were not acceptable. According to the considerable role of A. sieberi, S. barbata, and Z. eurypterum in the plant composition of the study area, it can be stated that the main variation in canopy cover of the study area is predictable on the basis of variation in precipitation over the vegetative season. In order to predict the variation in the vegetation cover of the study area, we can partially refer to variation in precipitation over the vegetative season but sometimes the occurrence of drought can affect the growth and development of the plant for a while and can change the relationships between climatic variation and changes in vegetation cover. Based on the results of this investigation, it can be concluded that Zygophyllum eurypterum as a perennial species showed the lowest variation to the precipitation and temperature while annual plants had the highest variation among the studied vegetative form.
As the duration of this study was restricted to 10 years, more suitable results for modeling on the basis of climatic variables may be obtained through long-term monitoring of changes in vegetation cover and climatic variation. Also, as environmental conditions are variable among regions, the results of this study can be generalized only to the same areas with similar climate, topography, soil, and vegetation cover. Similar studies are recommended throughout other areas as well as monitoring the species responses to climatic variation in areas with different conditions in the terms of precipitation and temperature regimes, topography, and soil properties.

Open Access This article is licensed under a Creative Commons Attribution 4.0 International License, which permits use, sharing, adaptation, distribution and reproduction in any medium or format, as long as you give appropriate credit to the original author(s) and the source, provide a link to the Creative Commons licence, and indicate if changes were made. The images or other third party material in this article are included in the article's Creative Commons licence, unless indicated otherwise in a credit line to the material. If material is not included in the article's Creative Commons licence and your intended use is not permitted by 
statutory regulation or exceeds the permitted use, you will need to obtain permission directly from the copyright holder. To view a copy of this licence, visit http://creativecommons.org/licenses/by/4.0/.

\section{References}

Abdolahi J, Arzani H, Savaghebi MH, Azimi MS, Naderi H (2012) The effect of precipitation fluctuations on canopy cover and range forage production in Yazd semi-steppe rangelands (Khud area 1378-1386). Res Instit Forests Rangelands 19(1):45-59

Abdolahi J, Savaghebi MH, Naderi H, Azimi MA (2011a) Influences of rainfall variability on yields of some plant species (case study: Mehriz rangeland of Yazad province). J Rangeland 5(3):280-291

Abdolahi J, Arzani H, Naderi H (2011b) The investigation of vegetation changes in relation to rainfall variation in Ebrahim Abad steppe rangelands, Yazd provience. Watershed Manag Res (Pajouhesh \& Sazandegi) 90:68-77

Akbarzadeh M, Mirhaji T (2007) Vegetation changes under precipitation in Steppic rangelands of Rudshur. Iran J Range Desert Res 13(3): 222-235

AnLin GU, Holzworth L, Yun JF (1994) Establishment of new entries of Psathyrostachys junceus in arid and semiarid areas in Inner Mongolia. Grassland China 5:12-14

Arzani H (1997) Project manual of range evaluation in different climatic regions of Iran. Research Institute of Forests and Rangelands, Tehran, p 30

Azarnivand H, Nikoo SH, Ahmadi H, Jafari M, Mashhadi N (2007) Investigation on environmental factors influencing distribution of plant species (case study: Damghan region of Semnan province). J Iran Nat Res 60(1):323-341

Bayat M, Arzani H, Jalili A (2016) Effects of climatic conditions on vegetation cover and production in steppe rangelands (case study: Alavijeh and Khondab-Isfahan province). Iran J Range Desert Res 23(2):357-372

Bradley BA, Mustard JF (2005) Identifying land cover variability distinct from land cover change cheatgrass in the great basin. Remote Sens Environ 94:204-213

Currie PO, Peterson G (1996) Using growing season precipitation to predict crested wheatgrass yields. J Range Manag 19:284-288

Damizadeh MB Saghafian A, Gieske (2001) Studying vegetation responses and rainfall relationship based on NOAA-AVHRR images. Proceding of 22nd Asain conference on remote sensing, 5-9 November 2001, Singapoure

Drawe DL (1999) Vegetation changes on the welder wildlife refuge, Texas. People and Rangelands: building the future. Proceeding of the VI International Rangelands Congress, Townsville, Queensland, Australia, 19-23 July, 1999. Volume 1

Ehleringer JR, Schwinning S, Gebauer R (1999) Water use in arid land ecosystems. In: Press MC, Scholes JD, Barker MG (eds) Physiological plant ecology. Blackwell Science, Boston, pp 347365

Ghelichnia H, Arzani H, Akbarzadeh M, Farahpour M, Azimi M (2012) Investigation on variation trends of vegetation and yield in rangelands of Mazandaran province (2001-2005). Iran J Range Desert Res 19(2):203-220

Hein L (2006) The impacts of grazing and rainfall variability on the dynamics of a sahelian rangeland. J Arid Environ 64:504-488

Hennessy DW, McLennan DJ, Williamson PJ, Morris SG (1998) Changes in characteristics of pastures in the coastal subtropical when grazing by cattle during low rainfall. Aust J Exp Agric 38(8):813-820

Herbel CH, Ares FN, Wright RA (1972) Drought effects on a semidesert grasslandrange. Ecology 1972(53):1084-1093
Hosseini SA, Khatir Namany J, Akbarzadeh M, (2014) Vegetation changes in semi-steppe rangelands of Golestan province(Case study: Maraveh tapeh). Iran J Range Desert Res 21(4):685-697

Jabbogy EG, Sala OE (2000) Control of grass and shrub above ground production in the Patagonian steppe. Ecol Appl 10(2):541-549

Jamieson PD, Porter JR, Wilson DR (1991) A test of the computer simulation model ARCWHEAT on wheat crops grown in New Zealand. Field Crop Res 27(4):337-350

Joneidi Jafari H (2009) Investigating the impact of some ecological and managerial characteristics on the carbon sequestration in Semnan Province, $\mathrm{PhD}$ Thesis in Rangeland, Faculty of Natural Resources, University of Tehran

Karabulu M (2002) An examination of relationships between vegetation and rainfall using weather variable. Range Manag 42(6) November

Karami P, Bandak I, Gorgin Karaji M (2019) Comparing the effects of continuous grazing and long term exclosure on floristic composition and plant diversity in rangeland ecosystems of Saral, Iran. Int J Environ Sci Technol 16:7769-7776. https://doi.org/10.1007/ s13762-018-02193-3

Karimi G, Yeganeh H, Abbasi Khaleki M, Moammeri M, Afra H (2015) Changes in Bromus tomentellus Boiss production and consumption in Kurdan rangelands, Alborz. Iran J Nat Resourc (J Range Watershed Manag) 68(2):359-370

Kashki MT, Shahmoradi A, Namdost T (2015) Investigation on variation and trend of vegetation fluctuations in desert ecosystems (case study: Jajrom area, North Khorasan). J Desert Ecosyst Eng 4(7): 87-98

Ligan Y, Cheng J, ChangDong S (1998) Research on drought indices for hebage of natural grassland on north slope of Tianshan mountains. Arid Land Geogr 21(4):68-73

Moghaddam M (1998) Range and range management. Tehran University Press $470 \mathrm{P}$

Moyo CS, Sikosana JLN, Gambiza J (1995) Recovery of eutrophic rangeland after a severe drought. Rangelands in sustainable biosphere. Proceeding of of the Fifth International Rangeland Congress, Salt Lake City, Utah, USA, 23-28 July 1995. Volume 1.: Contributed presentations., 1996: 385-386

Munkhtsetseg E, Kimura R, Wang J, Shinoda M (2007) Pasture yield response to precipitation and high temperature in Mongolia. J Arid Environ 70:94-110

Navarro J, Galt M, Holechek D, McCormick J, J. and Molinar, F. (2002) Long-term impacts of livestock grazing on Chihuahuan Desert rangelands. J Range Manag 55(4):400-405

Noy-Meir I (1973) Desert ecosystems: environment and producers. Annu Rev Ecol Syst 4:25-51

Paruelo JM, Lauenroth WK (1996) Relative abundance of plant functional types in grasslands and shrub lands of North America. Ecol Appl 6(4):1212-1224

Raynaud X, Leadley PW (2004) Soil characteristics play a key role in modeling nutrient competition in plant communities. Ecology 85: 2200-2214

Schwinning S, Starr BI, Ehleringer JR (2003) Dominant cold desert plants do not partition warm season precipitation by event size. Oecologia 136:252-260

Sharifi J, Shahmoradi AA, Nouri AV, Mohammadi D (2017) Vegetation monitoring in semi-steppe rangelands of Ardabil province (Aghdagh rangeland, Khalkhal). J Rangeland 11(3):283-293

Tasiu I (2020) Stress and defense responses in plant secondary metabolites production. Biol Res 52:39. https://doi.org/10.1186/s40659019-0246-3

Walter H (1979) Vegetation of the earth and ecological systems of the geo-bioshers. Springer-Verlag, Berlin Heidelberg New York Tokyo $274 \mathrm{pp}$

Zare Kia S (2015) Trend of Salsola laricina production and consumption in dry rangelands. J Plant Ecosyst Conserv 3(7):85-98 